\title{
Prof. Dr. Alexander Meng erhält das goldene Ehrenzeichen für Verdienste um die Republik Österreich
}

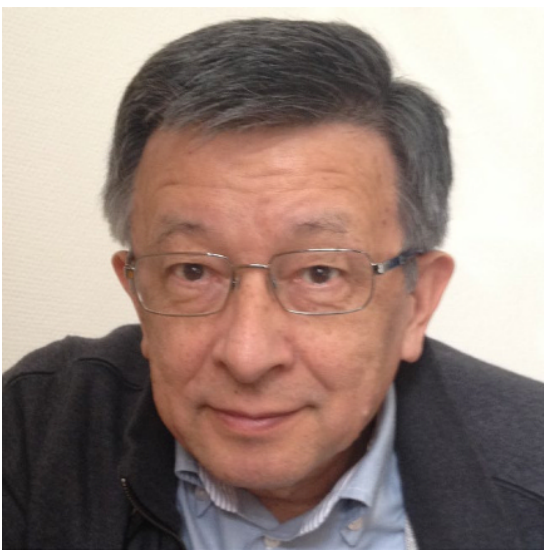

Abb. 1 Prof. Dr. Alexander Meng

DZA-Redaktion: Am 30.01.2019 wurde Prof. Dr. Alexander Meng, Facharzt für Neurologie/Psychiatrie, Vizepräsident der Österreichischen Gesellschaft für Akupunktur (ÖGA), das Goldene Ehrenzeichen für Verdienste um die Republik Österreich verliehen ( $\bullet$ Abb. 1 und 2$)$. Seit beinahe 50 Jahren stellt Prof. Meng sein umfangreiches Wissen und einen großen Teil seiner Zeit in den Dienst der ÖGA. Neben zahlreichen Übersetzungen von chinesischer Fachliteratur kann er auch auf eine Fülle von eigenen Büchern sowie Artikeln für die DZA blicken; die Erstellung der Kursskripte und die Erarbeitung der Kursinhalte kosteten ihn viel Zeit und Mühe. 1976 etablierte er den Arbeitskreis für Tuina-Therapie, der sich bis heute unter seiner Leitung um die Aus- und Weiterbildung von Therapeuten bemüht. Vor ziemlich genau einem Jahr wurde er von der Wiener Ärztekammer mit dem Silbernen Ehrenzeichen für sein weitreichendes Engagement geehrt.

Deutsche Zeitschrift für Akupunktur 2019. 62 (2): 141

https://doi.org/10.1007/s42212-019-0172-x

Online publiziert: 18. April 2019

(c) Springer Medizin Verlag GmbH, ein Teil von

Springer Nature 2019

\section{Auszug aus der Dankesrede von Prof. Dr. Alexander Meng, Vizepräsident der ÖGA}

„Man kann sagen, dass das Leben es mit mir gut gemeint hat. Noch vor der Matura kam ich von China nach Österreich, welche ich dann in Horn in Niederösterreich ablegen konnte. Das Interesse an der Medizin war schon immer da, unter anderem auch deshalb, da mein Vater selbst Arzt war in Österreich und China.

Während des Medizinstudiums in Wien lernte ich 1972 Prof. Johannes Bischko, den Gründer des Ludwig-Boltzmann-Instituts für Akupunktur, kennen. Bischko hat 1954 die Österreichische Gesellschaft für Akupunktur (ÖGA) gegründet. Gemeinsam konnten wir chinesische Akupunkturtafeln und Texte bearbeiten und vom Chinesischen ins Deutsche übersetzen. Dies war für mich der Anfang des fast 50-jährigen Brückenbaus zwischen meinem Mutterland Österreich und meinem Vaterland China.

Ein Höhepunkt meiner damaligen Ausbildung war das mehrmonatige Studium 1979 an der TCM-Universität in Shanghai, ermöglicht damals durch ein Stipendium des Bundesministeriums für Gesundheit und Umweltschutz Österreichs.

Im Jahre 1986 kam es zur wissenschaftlichen Anerkennung der Akupunktur durch den Obersten Sanitätsrat Österreichs, ein paar Jahre darauf folgte ein weiterer wichtiger Meilenstein der Akupunktur in Österreich: die Einführung des offiziellen Ärztekammerdiploms für Akupunktur.

Bis dato ist es mir vergönnt, einiges aus dem Schatz der TCM zum Wohle der österreichischen Bevölkerung zu vermitteln und auch an Studierende weiterzugeben.

Danke auch an alle meine Lehrer, Wegebegleiter, Förderer, an alle Anwesenden und natürlich danke ich auch meiner $\mathrm{Fa}$ milie, besonders meiner Frau Maria, für die Unterstützung und das Vertrauen in all den Jahren.

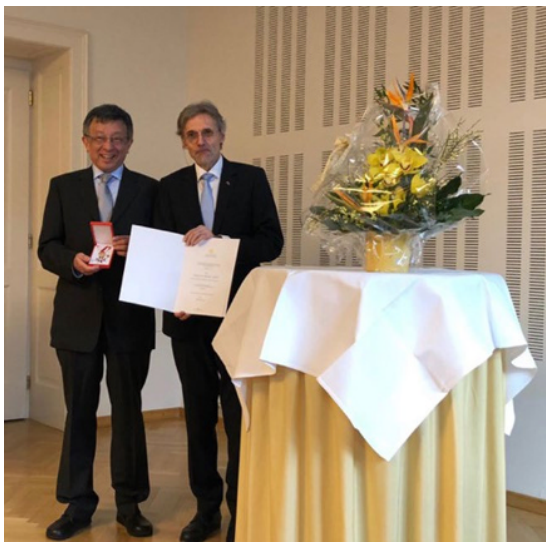

Abb. 2 Überreichung des Goldenen Ehrenzeichens durch Sektionschef Prof. Dr. Gerhard Aigner, Bundesministerium für Gesundheit Österreichs

Zum Schluss noch ein Zitat von Konfuzius:

Wer sich das Alte noch einmal vor Augen führt, um das Neue zu verstehen, der kann anderen ein Lehrer sein. 孔子曰: „溫故而知新, 可以為師 矣。“

\section{Dr. Thomas Ots}

Dr. Michaela Bijak 